\title{
Analyzing Existing and Targeted Culture Typologies in the Light of the Strategy Document in Foundation Universities: The Case of A Foundation University
}

\author{
Serdar Samur ${ }^{1, *} \&$ Merve Üsküplü ${ }^{1}$ \\ ${ }^{1}$ Faculty of Sport Sciences, Department of Sport Management, Istanbul Gedik University, Istanbul, Turkey \\ *Correspondence: Faculty of Sport Sciences, Department of Sport Management, Istanbul Gedik University, Çamlık \\ Mahallesi, Nazende Sokak, No:2, Çamlık Spor Tesisleri Karşısı, Kurtköy, Istanbul, Turkey. E-mail: \\ ssamur_2002@yahoo.com
}

Received: October 9, 2021

Accepted: November 3, $2021 \quad$ Online Published: December 10, 2021

doi:10.5430/wje.v11n6p40

URL: https://doi.org/10.5430/wje.v11n6p40

\begin{abstract}
Universities are multi-cultural, complicated, social education organizations. The presence of academic and administrative employees at these organizations might result in cultural differentiation, which is influenced by changing environmental conditions and social change dynamics. The purpose of this research is to determine the foundation university's dominant current and targeted cultural typologies using a foundation university as an example and to compare them to the university's target culture typology based on an analysis of the university strategy document. This comparison will aid in defining the perspectives of the organization's members through the concept of culture to achieve the university's strategic goals. Also, the examination of the strategy document, mission, the vision of the university and at the same time questioning the organization members' opinions about this topic fills a hole in the literature in terms of observing two sides of the coin; "rulers" and "ruled". In addition, we need to start to gain knowledge about foundation universities' organizational culture because we already know that cultural awareness is crucial for an organization lifetime and this knowledge comes from the analyses of it. Among the different approaches used throughout the world to define organizational culture, Cameron and Quinn's "Organizational Culture Assessment Instrument in Competing Values Framework" was employed in the study. This research was conducted with a multi-modal methodological approach by using both quantitative and qualitative methods together with the questionnaire and document analysis. According to the findings, university organization members' current (market-competition) and targeted (clan-collaboration) organizational culture typology interpretations diverge from the university's strategy on the same subject.
\end{abstract}

Keywords: organizational culture typology, OCAI, competing values framework, sports management

\section{Introduction}

When examining the organizational structures today, the questions asked about organizations have evolved. The question today is not "are organizations gonna change?", but "how they going to change?". This is because unchanging structures are called actless instead of persistent (Cameron \& Quinn, 2011). At this point determining and understanding the organizational culture is guiding for understanding the reason for the chosen work style in the organization, how to follow the path for change, and what kind of change can be experienced in the personal dimension (İra \& Şahin, 2011). Universities, which are social structures and kinds of organizations, have their own organizational culture and this organizational culture is an important factor for success (Beytekin et al., 2010). Furthermore, the dominant control mechanism in these institutions is organizational culture (Gizir, 2007). Therefore, understanding the organizational culture of educational institutions with the output of education mission for training labor force forms an important field of literature (Çimen \& Ekenci, 2002).

Studies in this field offer different perspectives on the subject. While this research contributes to the field based on a foundation university as a whole, it also stands out in the field with the multi-modal research method used within the scope of the research which allows melting a few research techniques in one pot. Some of the studies in the literature 
which include culture typology, organizational culture assessment instrument, competing values framework, and concepts close to them evaluate whether the culture in universities is sectional or whole, and some of them focus on communication and organizational commitment by including staff and students at universities at the same time. In addition, subjects such as culture, management, and performance are studied also (Murat \& Açıköz, 2007). Furthermore, studies in this field concentrate on subjects such as determination of organizational culture in universities (Akyol et al., 2020; Erdem \& İşbaş1, 2001; Murat \& Açıkgöz, 2007), comparison with the dominant organizational culture type and strategy in universities within the scope of Cameron and Quinn's Competing Values Framework (Berrio, 2003; Beytekin et al., 2010), determination of organizational culture in universities within the framework of Cameron and Quinn's “competing values framework" (Erdem et al., 2010; Lapina et al., 2015).

This study aims to identify the dominant current and targeted culture typology of a foundation university and to compare them with the target culture typology of the university in the light of the analysis of the university strategy document. The importance of this research underlies the aim because this comparison will help define the perspectives of the members of the organization through the concept of culture in the attempt to reach the strategic goals of the university. At this point, it should not be forgotten that organizational culture in education-based organizations consists of intense interaction between members and the perceptions of members should be consulted in organizational culture analyses.

Because of the looser structures of organizational cultures like university (Akyol et al., 2020), this research is important to transfer into practice. Also, the examination of the strategy document, mission, the vision of the university and at the same time questioning the organization members' opinions about this topic fills a hole in the literature in terms of observing two sides of the coin; "rulers" and "ruled". In addition, we need to start to gain knowledge about foundation universities' organizational culture because we already know that cultural awareness is crucial for an organization lifetime (Cameron \& Quinn, 2011) and this knowledge comes from the analyses of it.

Various methods have been defined to assess culture, Cameron and Quinn's "Competing Values Framework Organizational Culture Assessment Instrument (OCAI)" has been used to define university culture, and the resulting dominant current and targeted culture type has been evaluated together with the university vision, mission and strategy document. Determining the organizational culture with the OCAI which was created by Cameron and Quinn based on the Competing Values Framework helps to determine the holistic corporate culture image which consists of basic corporate culture elements such as dominant qualities, leadership, and strategic goals (Lapina et al., 2015). Determining the management approaches suitable for the type of culture in the evaluation will enable the development of a new management approach that combines and integrates the management actions with all its faculties in the strategic management of the university.

The questions to be addressed within the scope of the research are as follows;

-What is the current and targeted dominant culture of the foundation university within the scope of the concept of culture typology and are these cultural types parallel?

-What is the required dominant culture type according to the vision, mission, and strategy document of the foundation university?

- Are the dominant current and targeted culture typologies of the university parallel to the dominant culture typology determined in the light of the strategy document, the vision, and mission?

-If there is no parallelism, what kind of way can be followed to close the gap between the current culture type and the targeted culture?

\subsection{Organizational Culture and Strategy}

Before proceeding to the other stages of the research, there are a few terms used within the research that should be known. These terms are the organization, culture, organizational culture, and the relationship between organizational culture and strategy.

Culture is the values that have been carried by people from pre-ages to the present (Murat \& Açıkgöz, 2007), transferred through symbols, revived in people's behaviors, and strengthen the bonds of members of the organization by keeping the organization together (Erdem et al., 2010). In addition, culture plays a critical role in reducing collective uncertainties among members by creating a system of common meanings, conveying what is expected from members in the future, ensuring continuity in terms of core values between members as generations, connecting members, and long-term financial success (Cameron \& Quinn, 2011).

Organizational culture distinguishes the organization from others in terms of the values shared among the members 
of the organization (Erdem et al., 2010). While organizations exist within a culture, at the same time they produce culture themselves (Erdem \& Özen İşbaş1, 2001). Organizational culture cannot be easily recognized and can be called an invisible control mechanism (Gizir, 2007). It wouldn't be wrong to say that organizational culture is the glue that holds all the factors of the organization together (Cameron \& Quinn, 2011). But note that there is no best organizational culture. The state of being the best of organizational culture is related to different performances and their levels (Beytekin et al., 2010).

Over time, culture is developed within organizations to keep up with the changes in the environment, to survive against the problems experienced, or to be able to submit to these changes (Cameron \& Quinn, 2011). As long as this culture is successful in internal and external problem solving, it will be accepted and its basis won't be questioned or discussed. Then, it will be transferred to new members who'll be joining the organization (Beytekin et al., 2010).

Organizational culture and management are like two peas in a pod. Quinn suggested that there is a harmony between leadership style and culture type. Culture types are expressed by a specific leadership style that shares and reinforces the same values as that culture type (Cameron \& Freeman, 1991). These two institutions, which are complementary to each other, play an important role in the creation of processes in organizational practices and therefore in changes (Yaman \& Ruçlar, 2014). Managers can provide an easier shifting process by correctly identifying the culture typology (Cameron \& Freeman, 1991). Also, organizational culture can be used as a tool for orientation and control of employees (Yaman \& Ruçlar, 2014). At the same time, besides the role of being a tool for management, organizational culture is also manageable (İra \& Şahin, 2011).

Another output of organizational culture is that it can be instrumentalized to develop a strategy within the organization (Çimen \& Ekenci, 2002). It can be planned how to reach the targeted point via the definition of the type of culture that the organization has (Aydıntan \& Göksel, 2012). Before defining the mission of the organization, the strategy and culture should form a whole and should not be deteriorated in the organization (Beytekin et al., 2010). The harmony of organizational culture and strategy ensures the internalization of both elements within the organization, otherwise, counter situation creates difficulties at that shifting point. In addition, the supporting bond between organizational culture and strategy gains importance on issues that develop outside the organization such as competition, consumer, and technology (Murat \& Açıkgöz, 2007). If the goals and values are consistent, integrity can be achieved within the organization (Akyol et al., 2020). Although concepts such as strategy, market, and technology are important in organizational processes, a greater indicator of success is organizational culture (Cameron \& Quinn, 2011).

\subsection{Organizational Culture within Universities}

Organizational culture is also an important factor in universities which are organizations and it acts like a key to success (Beytekin et al., 2010). Relationships, working, decision-making, and problem-solving processes in universities are shaped by organizational culture (Beytekin et al., 2010), thus the dominant control mechanism in universities is organizational culture (Gizir, 2007). The main sources of university cultures are the beliefs, values, and assumptions of the founders of the organization and the learning experiences of the members of the organization in parallel with the development of the organization. These resources influence decision-making processes and shape behavior on a personal or organizational basis through discourses, current language, and organizational norms (Beytekin et al., 2010). Organizational culture in universities is also affected by national cultural and educational policies in the country (Lapina et al., 2015). From another perspective, universities are structures that ensure the transfer of culture to other generations, so the organizational culture of the university is really important (Bilir et al., 2003; Akyol et al., 2020).

Recognizing and understanding organizational culture in universities may not be easy due to the looser structures of these organizations (Akyol et al., 2020). Analyzing the organizational culture of a university is important in terms of adapting the organizational culture to its practices by its members to support continuous improvement. Common values, norms, practices, beliefs provide a framework for foreseeing the meanings of activities and actions on and off-campus (Beytekin et al., 2010). Cultural analysis should be at the center of the restructuring processes of universities (Gizir, 2007). From a strategic point of view, a common culture is one of the prior conditions for the realization of goals in educational organizations (Bilir et al., 2003). Since the organizational culture in educational organizations is formed in the intense interaction between the members of the organization, it is necessary to determine the perceptions of the members about this issue while analyzing the organizational culture in these institutions (Erdem \& Özen İşbaş1, 2001). Understanding the organizational cultures of universities is also an important condition for their effective management (İra \& Şahin, 2011). 


\section{Methods}

In this research, the "multi-modal research method" was used and in this way, two methods, questionnaire and document analysis, were used in the same research.

\subsection{Multi-Modal Research}

This method, which was widespread in the late 1980s, can include very different approaches related to the research process, which can involve both qualitative and quantitative elements. Despite questionnaires and interviews being the most common versions of multi-modal research, this process can be even more complicated. Qualitative and quantitative analysis within the same research can enrich the findings (Kara, 2020). While qualitative research allows to examine behaviors, attitudes, and experiences in detail and to ask descriptive questions such as how and why, rather than the measurable characteristics of the investigated phenomenon or people (Kıral, 2020), quantitative researches are kind of researches that the researcher has a clear opinion about which data is looked for, all the details of the research are planned before data collection, enable to collect numerical data with tools such as questionnaires (McCusker \& Gunaydın, 2014).

In this way, a framework method that includes more than one method offers different ways for us to understand the world. But the multi-modal method does not argue that it is better than a single-model method. Which model and method to use depends on the question and context of the research. To reveal robust multi-modal research, the method to be used and the appropriate theoretical framework should be properly planned at the beginning of the research (Kara, 2020).

The reason why we used this research method is, this kind of multi-method researches allow the researcher to use different methods correspondingly, with the same purpose and non-integrated but at the end of the research, researcher can collect the data together and analyze it collectively. The important point here is the confusability of multi and mixed-methods in terms of terminological, conceptual, and methodological. However, the difference between mixed and multi-methods is, multi is not be restricted to combining qualitative and quantitative methods like mixed methods. It lets researcher use all the possible combinations of methods (Angueral et. al., 2018) as long as the used methods won't dominate one another and will follow the steps of those requirements; "identification of the research question, collection of data, analysis of data, and interpretation of results" (Angueral et. al., 2018, p. 2762).

\subsection{Questionnaire: Organizational Culture Assessment Instrument}

The questionnaire, which is applied verbal or in written, is a low-cost research method that is applied to get quantitative or qualitative information on a wide scale and provides access to information in a short time (Arikan, 2018). Questionnaire questions were taken from the Organizational Culture Assessment Instrument of which validity and reliability were proven, and university faculties were visited one by one and the questionnaires were applied face-to-face to academic and administrative staff based on consent. In addition, the ethics committee report was also obtained before collecting the research data. The way of application of this questionnaire to members of the organization is clearly described by Cameron and Quinn. Just as there is no correct answer in the culture typology, the questions in this questionnaire do not have a correct answer and scoring.

There are two parts to the survey. The first part consists of questions of age, gender, and role in the organization to find the personal and professional qualifications to whom fills the questionnaire. In this part, the person who fills the questionnaire answers open-ended and multiple-choice questions. The questions do not have an identity-determining content such as the names and surnames of the people who applied the survey. Individuals remain anonymous. In the second part, there are 6 dimensions in the questionnaire, and each of the 6 dimensions consists of 4 themes. These 6 dimensions proceed as two repetitions, the current situation and the targeted. For each question, the total score of the current and targeted columns is 100 , and the person filling the questionnaire allocates the 100 points according to propositions' suitability to the reality or objectives. The highest score will be given to the item that shows the most similarity to the organization among these items. In the current situation, the highest score will be given to the item most appropriate to the current situation of the organization, and the highest score in the targeted situation will be given to the item that is proper to the situation that the member of the organization wants the organization to be.

\subsection{Organizational Culture Assessment Instrument}

The Organizational Culture Assessment Instrument (OCAI) reflects the basic cultural values in the organization and the assumptions of the members about how the organization functions with six content dimensions: the dominant characteristics of the organization, leadership styles in the organization, work environment and behaviors, organizational commitment, the strategic attitude of the organization, and the reward mechanism (Cameron \& Quinn, 2011). 
OCAI is based on the "Competing Values Framework", which is highly compatible with studies on interpreting situations within the organization, the behavior patterns of the organization member, organizing inferences about their values and assumptions (Cameron \& Quinn, 2011). Many researchers such as Quinn and Rohrbaugh, Cameron and Freeman, McDonald and Gandz have studied organizational typologies in the light of the competing values model (Murat \& Açıkgöz, 2007). Cameron and Quinn, Competing Values Framework is a theoretical model and they developed an organizational culture framework on this model. This model and framework are used to build an organizational culture profile by revealing the dominant culture typology characteristics of the organization with the use of OCAI by organization members (Berrio, 2003). At the same time, the scale that is often used in the processes of culture alteration in organizations is the OCAI. OCAI is a scale designed to determine the current culture of the organization as the first step and the targeted culture as the second step. This scale is used not only in organizational culture, but also in measuring factors such as educational success, management, leadership, and teacher success, and in educational organizations, universities, and sports teams (Cameron \& Quinn, 2011).

The Competing Values Framework approach developed by Cameron and Quinn has been shaped by a study on main structures at effective organizations. Thus, a 2-dimensional and 4-cluster schema has emerged. One of the dimensions emphasizing flexibility, initiative, and dynamism is distinguished from others that emphasize, order and control. The other dimension which emphasizes integration and unity distinguished from the other which emphasizes differentiation and competition (Cameron \& Quinn, 2011). With the combination of the two dimensions, 4 clusters are formed, each with different values. The four clusters contain the core values of the organization. When these 4 clusters are compared crosswise, they are competitive and opposite of each other. Hence, it gets the name "Competing Values Framework". According to the values in the 4 clusters, the dominant culture type of the organization emerges (Cameron \& Quinn, 2011).

Organization types in 4 clusters are hierarchy-control culture, market-competition culture, clan-collaboration culture, and adhocracy-creative culture. In organizations with a hierarchical-control culture, productivity, reliability, elimination of problems, and predictability of outputs are determined as the main tasks. The limits of decision-making authority are demarked. Rules and processes are standard. Success is built on control and accountability. Procedures are important. The focus is on merit. Market-competition culture is a culture in which organizations become markets, the external environment is the focus instead of internal functioning, and concepts such as economic market mechanisms and competition come to the fore. Profitability, final result, success, customer assurance are the goals. Productivity and market leadership are important. Clan-collaboration culture is common in family-type organizations and this organization resembles an extended family. It is important to be consistent, to be a participant, the importance of the individual and we-feeling, and teamwork. Employees' participation in processes within the organization, their speaking up abilities, and empowerment are encouraged. Loyalty and commitment of employees are essential. Customers are seen as stakeholders. The mission of the leader of the organization is to be a mentor. Innovation and pioneering are the basis of success in adhocracy-creative culture. It has goals such as producing new products and services, being ready for the future, using technology at the most advanced level. Organized anarchy, disciplined creativity, adaptability, and flexibility are important concepts. Innovation must be adapted immediately. It does not adopt a centralized management approach and hierarchical order. Individuality is important (Cameron \& Quinn, 2011).

The definition of managers according to their culture types is done with the four culture typologies we use. The most important change for organizational culture shift will occur within the managers and behavior of members of the organization. Although it is difficult to change managerial styles, not impossible (Cameron \& Quinn, 2011).

While one of these organizational types can be dominant in an organization, one or more models can also be dominant (Cameron \& Quinn, 2011). The presence of different typological features in an organization at the same time reveals that the organization is in a healthy organizational structure (Murat \& Açıkgöz, 2007). The absence of a dominant type as a result of the questionnaire in an organization indicates that the members of the organization participating in the questionnaire are not clear about the culture or that these organizational types are equally dominant in that organization. An equal dominance in all 4 sections is not a necessity. At the same time, different types of culture may emerge at different levels of dominance within the same organization. Harmonious cultures are not a condition for organizational success, but they do play an important role in high performance. In addition, maladaptive culture can also be a signal that change is needed in an organization (Cameron \& Quinn, 2011). However, regardless of the dominant culture type in an institution, productivity level and culture type are related (Cameron \& Freeman, 1991).

This is the culture shift preparation process. The organizational culture profile that comes out after the application of 
OCAI provides a compass to the researcher for the possible cultural change in the organization. OCAI reveals a map for some points such as what is organizational culture, which point it wants to go, which point it should go, and how to go to that point. In this process, many factors related to culture should be recognized and changed if necessary. In the process of organizational shift and change, the failure which is specific to culture-shifting could affect the other shifting units (Cameron \& Quinn, 2011). Building consensus on the current culture will prevent an unsuccessful shifting attempt (Lapina et al., 2015).

\subsection{Document Analysis: Strategy Document}

Document analysis, which is a qualitative research method, is the analysis of the content of written documents. The written document can be printed or electronic. These documents were not interfered with by the current research (Kiral, 2020). In this section, the Strategy Document, which is open to everyone on the website of the foundation university has been examined in detail. During the analysis, the information contained in the document was not interpreted.

The strategy document that covers the years 2019-2023 runs at the foundation university. In the preparation process, the principles of participation, transparency, realism, and measurability were adopted and internal and external stakeholders participated in that process. The strategy document focuses on objectives, goals, performance indicators, strategies, target risks, control activities, and costs. To prevent this plan from being just a document and to transform it into a guide that will help the university reach its mission and vision, the goals and objectives will be revised in light of the results routinely. The university defines itself as an organization that is innovative, entrepreneurial, researcher, pioneer, dynamic, managing transparently, reliable, open to criticism, where administrators and faculty members adopt an open-door policy, where there is freedom of expression and corporate values are adopted. It also acknowledges that organizational identity is in the evolving phase and defines itself as a young and dynamic university.

The slogans used in the strategic planning document of the university are as follows; "Our Job, Your Future", "We Are Different, Equal But Together We Are Stronger", "Innovative, Dynamic and Hopeful University", "Open to Development, Sensitive to Society". "Researcher and Difference Maker in the Global World", "Always Ahead for Their Goals". The differentiation strategy adopted by the university is an important part of its strategic plans. The foundation university focuses on $45 \%$ research, $40 \%$ education, and $15 \%$ entrepreneurship actions. According to the university's strategy document, most of the universities in Istanbul are education-oriented and this is the reason the foundation university involved in that research chose the research strategy as an alternative. To realize this strategy, foundation university aims to increase multidisciplinary studies at the university, implement projects and research, and increase the quantity and quality of education programs.

Its next five-year strategy goal is to increase entrepreneurship. To do this, the foundation university tries to be in close dialogue with the business world. However, the educational field is not overlooked. For field development, departments of the university and academic staff will be updated continuously. It is a priority to increase the studies of academicians in university programs and to reward their success.

The mission of the university is determined "to be an education and research university that can produce universal values by using scientific knowledge in the integrity of human, nature and technology.", and the vision of the university is determined "to be a global university which is innovative, difference-making, value-producing, perfectionist that raises individuals who can shape the future with its distinguished teaching staff through sustainable education programs.". The basic values of the university are "devotion to the principles of democracy and law, respect for ethical principles, quality and efficiency, differentiation and making a difference, cooperation and integration with all stakeholders, innovation, creativity and entrepreneurship, cultural, artistic and social sensitivity, commitment to sustainable living principles, environmental and nature sensitivity" (Strategy Development Department, 2019).

In line with this information, 5 goals in the university strategy document and 25 objectives for the realization of these goals were determined. The goals were determined as research orientation and innovative identity, internationality, sustainability, social and economic benefit orientation, corporate identity, and capacity building. In line with these goals, the objectives are to increase the number of studies published in SCI/SSCI and international refereed journals, the number of projects, the number of areas and venues and their qualifications, and the number of qualified students, the number of international education-training activities, satisfaction, the number of internal programs for the institution, and the number of studies that have social benefits. 


\section{Results}

OCAI has been applied in the foundation university. For each question 6 A's current, 6 B's current, 6 C's current, 6 D's current, 6 A-targeted, 6 B-targeted, 6 C-targeted, 6 D-targeted collected separately and divided into 6 . Afterward, the results were collected for each letter and divided by the number of respondents. So, the organizational culture typology was obtained. Accordingly, the letter with the highest numbers coincided with an organization typology. The results are shared below.

\subsection{General Current and Targeted Culture Typology of A Foundation University}

As a result of the Organizational Culture Assessment Instrument application conducted with a total of 113 people consisting of the administrative and academic staff of the foundation university, correct data were collected for 81 people.

When the data is examined, as seen in Figure 1, it is A 23.415, B 21.810, C 26.862, D 26.306 in the current situation, and in the targeted situation A 27.705, B 24.681, C 22.026, D 24.493. In this case, the dominant current organization culture typology is C, market-competition, and the dominant targeted organization culture typology is, A, clan-collaboration.

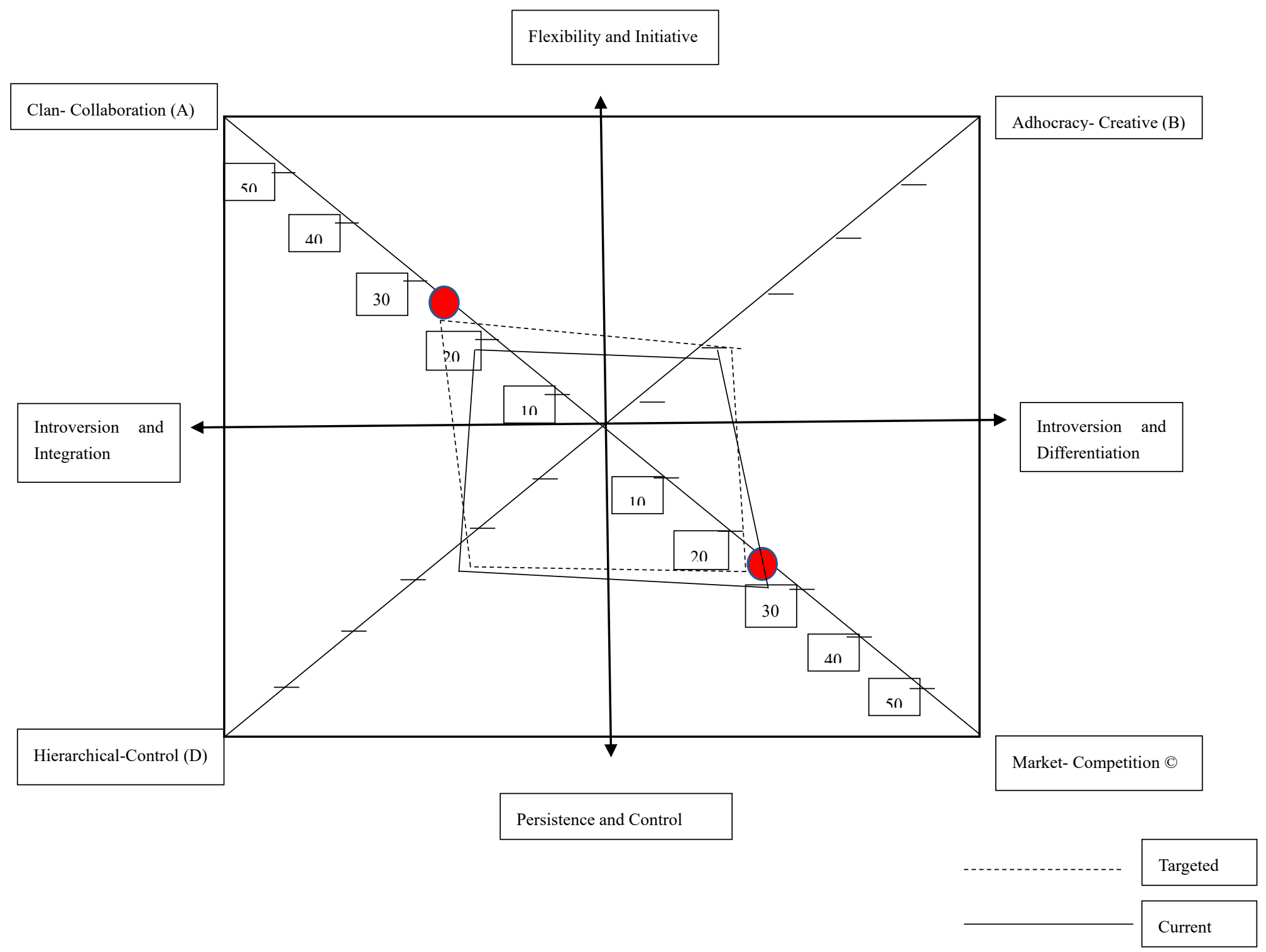

Figure 1. The Foundation University General Current and Targeted Culture Typology 


\section{Discussion}

Organizations need to have the cultural awareness to maintain a stable course of life. However, the dominant culture may not be realized until the organization meets any difficulties. But determining the organization's dominant culture is vital data in terms of determining the need for self-updating. The environment, competition conditions, technological and social developments in the world may differentiate the organization's envisioned strategy document and the dominant culture type. This differentiation can only be revealed by the analysis of the knowledge of the members of the organization. In addition, harmony and organizational continuity can not be achieved unless the goals and objectives in the strategy document are in line with the dominant culture typology.

When we look at the strategy document of the foundation university within the framework of this research, we see a picture that is the same from some perspectives and different from others. Although the motto in the strategy document refers to the clan-collaboration culture typology with the expression "we are stronger together", the main target strategic point is explained with expressions such as "innovation, dynamism, researcher, making a difference, being targeted, open to development, looking to the future with hope.". The reason for this is that although there is a dominant culture in organizations, not only one culture typology will be effective, and more than one dominant culture type will be together for a healthy organization. Therefore, in the strategy document, which also refers to the clan-collaboration culture type, we see that the dominant targeted culture is parallel to the adhocracy-creative culture typology. In addition, as it can be understood from the $45 \%$ research, $40 \%$ education, and $15 \%$ entrepreneurship targeting in the strategy document, the dominant cultures of the university are the adhocracy-creative and market-competition culture typologies. The goal of being a research university is also related to the dominant culture typology, and it is repeatedly emphasized in the points of strategy, mission, and vision. In addition, we know from the mission and vision that the foundation university tries to be an education and research university and a global university.

Although this foundation university's general current organizational culture typology and strategy document, vision, and mission do not meet on common ground, the current dominant culture typology market-competition catches the document which is slightly less dominant in comparison with adhocracy-creativity in the strategy document. Also, this result is not in line with previous researches. For example In Turkey, the dominant culture in higher education institutions has emerged as a hierarchy-control culture (Beytekin et al., 2010). In another study, it was revealed that two-thirds of the universities and colleges participating in the research had clan culture. In the same study, staff who provided data for the study declared clan culture to be the most influential type of culture for universities and colleges. Therefore, the culture typology overlaps with the current situation and the targeted situation (Berrio, 2003).

Returning to the results of this research, the strategic goals have not been fully achieved. In this case, the members of the organization say that the university has become a market and the internal functioning focuses on the external environment. In addition, concepts such as the economic market and its mechanisms, competition, profit, guaranteed customer, market leadership gain importance here. The fact that the university is subject to a fee appears as a questionable point in the development of this opinion. At the same time, according to organization members, the targeted organizational culture typology of the university is clan-collaboration. The members of this organization want to be in an organization that resembles a large family. The sense of individuals and us have to be important, the participation of the members in the organization should be at the forefront, and loyalty and commitment should be the basis.

In summary, the questions of this research which look for the answers to are the current and targeted dominant culture of the foundation university within the scope of the concept of culture typology, their parallelism, required dominant culture type according to the vision, mission, and strategy document of the foundation university, the parallelism of it with the result of the questionnaire, what kind of way can be followed to close the gap between the current culture type and the required culture. Through the research conducted with the academic and administrative staff of the university, the characteristics of the dominant current culture and the targeted culture types are explained in the light of the university's strategy document below.

-The university's dominant current culture typology is market-competition as in Figure 1 and this result does not fully meet the organizational culture typology envisaged in the strategy document,

- It is understood that employees are in a need for transition to the clan-collaboration type, in contrast to the dominant culture typology of strategy document which is adhocracy-creative.

In conclusion; it is understood that the current and targeted culture typology in the university strategy document does not fully describe the cultural environment that the employees currently have and does not meet their future 
expectations. The foundation university covered in this study is 11 years old and the strategy document has been existing since 2019. And at this point, it has failed to meet the vast majority of its aims.

As a result of this study, considering the culture typology data contained, it is seen that there are two ways to follow which are to reach the culture typology directed by the university strategy document or to change the culture typology in line with the expectations of the employees. As the authors' suggestions to achieve this change, on the way to reach the culture typology envisaged in the strategy document are;

-Organizing seminars for university staff to raise awareness among employees on cultural variables,

-Informing the employees about the university strategy document,

-Organizing a workshop so that administrators who are in a managerial position have more information about the dominant culture type in the strategy document,

-Making personnel selection by considering the targeted dominant culture type in the recruitment processes,

-Assigning the experts who will manage the change and the people who will be in the leadership position for the transition to the envisaged cultural typology,

- To hold informative workshops on management approaches for the dean's offices, which are senior administrators.

The second way, to update the vision, mission, and strategies in line with the expectations of the employees, the suggestions to include in strategical goals are,

-The organizational structure should be likened to a large family structure.

-The sense of "us" within the organization should be strengthened.

-Concepts such as teamwork, consistency, and participation should be integrated into the strategy document, vision, and mission.

-The organization should organize programs for its members to participate in.

-The authority of the members of the organization should be increased.

-Students who provide income to the organization should also be called stakeholders.

-The leader should become a mentor.

-Clan-collaboration organizational culture typology features can be learned by the decision-making mechanisms, and mottos such as "together we are strong" can be included in the purpose, vision, and mission, especially in the strategy document.

-In addition, the vision and mission have to be revised according to these strategic goals.

During collecting data, we faced with few limitations. Especially the number of face-to-face surveys decreased due to the summer period, pandemic conditions, and the intensity of the use leave of absences during the summer period, and all 287 academic and 94 administrative staff could not participate in the survey. In addition, the reason for the difference between the number of people surveyed and the number of correct data is the mathematical process of the survey. Due to the questionnaire filled without considering the situation which is the total score should have been 100 , could not reach 100 points or exceeded 100 points. Therefore, those questionnaires could not be included in the scoring system.

This research guided us to draw a picture of the organizational culture of foundation universities based on the case of a foundation university and gave us a starting point to examine others. In this way, it helped to start filling a hole in the literature that already gave us information about public universities. Further from this point, besides examining foundation university culture in general, all faculties could be examined separately to gain a better and deeper understanding of organizational culture. Also according to our findings and suggestions creation of a booklet would be helpful to other universities who would like to start an organizational cultural changing process.

\section{References}

Angueral, M.T., Blanco-Villaseñor, A., Losadal, J. L., Sa'nchez-Algarra, P., \& Onwuegbuzie, A. J. (2018). Revisiting the difference between mixed methods and multimethods: Is it all in the name? Qual Quant, 52, 2757-2770. https://doi.org/10.1007/s11135-018-0700-2

Akyol, B., Tanrısevdi, F., Gidiş, Y., Dumlu, N. N., \& Durdu, İ. (2020). Organizational Culture at University: A 
Sample of a State University, Faculty of Education. Journal of Qualitative Research in Education, 8(1), 18-38. https://doi.org/10.14689/issn.2148-2624.1.8c.1s.2m

Arıkan, R. (2018). A Generale Review on Interview Techniques. Haliç University Journal of Social Sciences, 1(1), 97-159.

Aydıntan, B., \& Göksel, A. (2012). Dynamics of Organizational Culture Differentiatiın the Axis of Organizational Culture Types of Cameron-Quinn-Freeman. Niğde Üniversitesi İ̈BF Dergisi, 5(2), 53-62.

Berrio, A. A. (2003). An Organizational Culture Assessment Using the Competing Values Framework: A Profile of Ohio State University Extension. Journal of Extension, 41(2).

Beytekin, O. F., Yalçınkaya, M., Doğan, M., \& Karakoç, N. (2010). The Organizational Culture At The University. Educational Research Association The International Journal of Educational Researchers, 2(1), 1-13.

Bilir, P., Ay, Ü., \& Çelik Gürbüz, T. (2003). A Study of Organizational Culture In Physical Education and Sports Schools. Spormetre Journal of Physical Education and Sport Sciences, I(2), 117-128.

Cameron, K. S., \& Freeman, S. J. (1991). Cultural Congruence, Strength, and Type: Relationships to Effectiveness. Research in Organizational Change and Development, 5, 23-58.

Cameron, K., S., \& Quinn, R., E. (2011). Diagnosing and Changing Organizational Culture (3rd ed.). Based on the Competing Values Framework, Jossey-Bass.

Çimen, Z., \& Ekenci, G. (2002). Organizational Culture in Physical Education and Sport Departments. Gazi Journal of Physical Education and Sports Sciences, VII(2), 41-56.

Erdem, F., \& Özen İşbaşı, J. (2001). Organizational Culture in Educational Institutions and The Perceptions of Student Subculture. Akdeniz I.I.I.B.F. Dergisi, (1), 33-57.

Erdem, R., Adigüzel, O., \& Kaya, A. (2010). Organizational Culture Types That The Academicians Perceive and Prefer in Relevant With Their Institutions. Erciyes University Journal of Faculty of Economics and Administrative Sciences, 0(36), 73-88.

Gizir, S. (2007). A Review on Organizational Culture and Organizational Communication in Universities. Educational Administration: Theory and Practice, 50, 247-268.

İra, N., \& Şahin, S. (2011). A Study of Validity and Reliability of Organizational Culture Scale. Sosyal Bilimler Dergisi, 9(1).

Kara, H. (2020). Creative Research Methods: A Practical Guide. Policy Press.

Kıral, B. (2020). Document Analysis As A Qualitative Data Analysis Method. Journal of Social Sciences Institute, 8(15), 170-189.

Lapina, I., Kairiša, I., \& Aramina, D. (2015). Role of Organizational Culture in the Quality Management of $\begin{array}{lllll}\text { University. } & \text { Procedia-Social and Behavioral }\end{array}$ https://doi.org/10.1016/j.sbspro.2015.11.472

McCusker, K., \& Gunaydın, S. (2014). Research using qualitative, quantitative or mixed methods and choice based on the research. SAGE Journals, 30(7), 537-542. https://doi.org/10.1177/0267659114559116

Murat, G., \& Açıkgöz, B. (2007). An Analysis Of The Managers' Perceptions About Organizational Culture: The Case Of Zonguldak Karaelmas University. ZKU Journal of Social Sciences, 3(5), 1-20.

Strategy Development Department. (2019). Istanbul Gedik University 2019-2023. Strategical Plan. Retrieved from https://www.gedik.edu.tr/wp-content/uploads/stratejik-plan-2019-2023.pdf

Yaman, E., \& Ruçlar, K. (2014). Organizational Silence in Universities as the Predictor of Organizational Culture. Journal of Higher Education and Science, 4(1), 36-50.

\section{Copyrights}

Copyright for this article is retained by the author(s), with first publication rights granted to the journal.

This is an open-access article distributed under the terms and conditions of the Creative Commons Attribution license (http://creativecommons.org/licenses/by/4.0/). 